WAITING TIME TARGETS AND

INFORMAL PROFESSIONAL NETWORKS IN THE ENGLISH NHS 


\title{
Waiting Time Targets and \\ Informal Professional Networks in the English NHS
}

\begin{abstract}
Purpose

This paper examined the relationship between key actors in a specific organisation, and the informal professional networks that connect said actors. It used Pragmatic Constructivism as a research paradigm together with concepts borrowed from the theory of social networks to investigate how these actors responded to a particular set of non-financial performance targets.
\end{abstract}

\section{Design/methodology/approach}

The implementation process used to achieve waiting time performance targets in the Accident \& Emergency department was observed as part of an in-depth study at a large English National Health Service hospital. The main sources of data were face-to-face interviews with key actors, documentary archival evidence, and the researchers' field observation diaries.

\section{Findings}

The results indicated that there were structural holes between the management topos and inter-organisational professional topoi. Professional connections between key actors had allowed them to generate their own topoi in responding to new performance measures. These topoi influenced the perceptions of other actors in relevant networks, as well as the implementation practices. As a result of this influence, a new managerial topos was formed.

\section{Research limitations/implications}

This is a single site in-depth case study hence the findings are not generalizable.

\section{Practical implications}

This study demonstrated just how influential some key actors can be in shaping the implementation of performance measures.

\section{Originality/value}

This paper contributes to Pragmatic Constructivism by providing evidence on the influence of informal professional networks and structural holes in shaping organisational topos. 


\section{Introduction}

This paper focused on key actors' interaction with a set of newly-implemented, nonfinancial performance indicators in a public-sector setting. The background of this topic is the influence of current trends in New Public Management (NPM), with reference to non-financial indicators. The number of, and the emphasis on, non-financial performance indicators is increasing in almost all areas of public services in England. It is therefore essential to study how these indicators influence management practices in particular settings. The theoretical framework used in this study is inspired by the newly emerging paradigm of Pragmatic Constructivism for practice in contemporary studies of accounting (Norreklit et al., 2012). The paradigmatic base of practice is an important element in this paper as it helped to explain, understand and analyse the performance management practices. The paradigm was used to examine professional networks and to thus establish how actors' interaction and information sharing through professional networks influence their understanding of new performance measures and the actions they take to achieve performance targets. For this purpose, certain concepts from the theory of social networks (Burt, 1992) were utilised and incorporated into the four dimensions of Pragmatic Constructivism (PC).

PC is strongly embedded in the practice of accounting and its pragmatic aims; as such, it is clear that accounting is real. With PC, it becomes possible to analyse the dynamic relationship between new practices and norms of accounting. Indeed, PC is in stark contrast with, for example, critical studies of accounting, as the former claims that valid accounting practice exists; it also provides a framework through which to come to grips with the internal and external factual possibilities of producing a truth and value apt practice of accounting out of factual possibilities. It offers a mediating model in which realism is retained as the pragmatic criteria of success of the organisational actors' 
construction (Norreklit et al., 2016). Valid accounting measures can only be reconstructed from and in local practice. If there are socially dominating forms of accounting, then PC also provides a framework for the evaluation and validation of these, relative to the subjective goals of organisational actors and their organisations' objectives. Norreklit et al. (2016) invited further conceptual and empirical studies of PC to expand the general understanding of management accounting in relation to actors' construction of functioning organisational practices. This paper has responded to their call by delivering an in-depth study of change in practice and how it aids in the meeting of new performance targets. The investigation referred to both local, internal and external dynamics under which actors are expected to react and find ways to make new performance measures real. In addition to this, the paper aimed to lean on concepts from the theory of social networks in order to break down the process and enrich PC by using these concepts to explain actors' construction of reality.

The case study was a large hospital run by the English National Health Service (NHS). Key actors in the organisation were observed for 12 months and interviewed during the process of implementing a set of non-financial targets. The aim was to understand how key actors managed these new measures and how the measures were affected by their professional interactions. The findings revealed that professional networks provided the actors with a new set of facts and possibilities in line with their professional values. The actors then utilised said new facts and possibilities to improve integration between the four dimensions of PC; indeed, this allowed them to devise a practically valid solution which was used to meet the targets. In other words, the actors succeeded in producing a practically valid solution by integrating new facts and possibilities acquired through professional networking outside the organisation.

The results indicated that clinicians and service managers in the hospital served as key 
actors connecting the organisation to the inter-organisational professional network. In this network, professionals had generated their own understanding of the performance measures and found new ways to implement them. According to PC, this was a new professional topoi, and was influential in shaping the perceptions of key actors in the hospital under study. As a result, these actors learnt new methods they could use to hit the performance targets, and these were adapted to the hospital under study. This change resulted in a new management topos in the case study organisation and success in achieving new performance targets.

In terms of how the present paper is organised, this brief introduction is followed by a summary of certain characteristics of NPM, as well as the current performance measurement systems in public sector organisations. The third section then delivers an in-depth explanation of the research problem. The fourth section introduces the research paradigm of PC and explains relevant concepts borrowed from the theory of social networks. This is followed by the methodology section and background information about the case study organisation. The findings are then presented, with subsequent discussion and final comments concluding the paper.

\section{New Performance Measures, Systems Thinking and Changing Role of Managers}

This section presents a discussion of the methodological approach followed in order to implement non-financial performance measures in NPM. It focuses on health services and discusses certain aspects of the systems approach as a performance management methodology. Following this, the networking and information sharing aspects of NPM are explained. Conclusions drawn from these discussions are then used to justify and present the research questions at the end of this section.

\subsection{NPM and New Performance Measures}


Traditional bureaucratic public administration has long been characterised by inefficiency and limited accountability, with measures of performance that were ad hoc and far from systematic (Hughes, 2003). NPM evolved as a response to these critics. As explained and discussed, to some extent, by Hood (1991, 1996, 1998) and Pollitt and Bouckaert (2000), NPM brought the following to public sector management: enhanced accountability practices in line with political drivers to make the public sector more 'business like', turning users of public service into 'customers', and an increasing emphasis on managing these quasi markets through competition and performance measures (McLoughlin et al., 2001).

Reforms in managing these services as 'quasi' markets meant that performance measures would replace the market forces. These measures included a large set of financial and non-financial metrics at all levels of public sector management, from central management units (such as Prime Minister's Delivery Unit in UK) to individualbased services in organisations (such as schools, universities and hospitals). According to Hood and Beaven (2005), this approach to managing performance could be described as a 'homeastatic' control system. In such a system, desired results, or performance targets, are specified in advance in measurable form at the political centre, following which a certain kind of monitoring system measures performance against these specifications. Some feedback mechanisms are then linked to measured performance through various monitoring and regulatory institutions which are established through political power.

This approach was appealing to public sector managers because it gave managers of complex, pluralistic, professional-heavy public organisations an explicit role. It is evident from various studies concerning the public sector in general, and health services 
in particular, that individuals' attitudes, as well as the managerial approaches through which the performance measures are managed in organisations, vary greatly; indeed, this is because reactions are highly dependent on managers' motivation and responses to these targets (Hood and Beavan, 2005). According to Hood (2006), this approach caused inconsistency in several parts of the UK public sector.

Managers' attitudes towards and their motivation to achieve new performance measures constitute a key dimension of NPM. This view supports the quasi markets understanding, which uses new performance measures as the main intermediary (Ferlie et al., 1996). This makes new performance measures extremely important and a priority for public sector organisations. It is therefore essential and valuable to study management practices, and address and manage performance targets, particularly the settings of the public sector.

The next section introduces two contrasting methodologies for managing performance measurement in public-sector settings. These methodologies will be further explored later in the paper, as explained below.

\subsection{Contrasting Methodologies for Managing Performance Measurement}

According to Cinquini et al. (2013), the management methodologies which should be used to design performance measurement models and put them into practice have implications for the adopting organisation. These authors used a practical methodology as their conceptual framework. A practical methodology provides a framework which details the knowledge creation process and the actions employees must take when measuring and managing performance. They described two contrasting methodologies for managing performance measurement, both of which affect employee motivations 
and actions differently. One of these methodologies is fairly similar to the 'systems approach', while the other is more of an 'actor's approach'. These distinct methodologies are summarised below, as such a summary will make it easier to look for these methodologies in the case study data. The discussion section at the end of the present paper uses this categorisation when referring to the findings of the study.

\subsubsection{Systems Approach}

The systems approach is rooted in realism and objectivity, and hence does not take into account individualistic intentions, perceptions, or the understanding of employees. Employees are considered a system component whose role is to serve the intentions of the whole organisation. The individual employee does not have personal objectives. Instead, only the organisational system has objectives to which individuals must subscribe. Within the systems approach, the objective of the management control system is to describe the organisational system in order to control and monitor said system, including its components and its relations to the environment. The method places little emphasis on any implementation problems or special local or individual conditions. Winning support is seen as unproblematic, as the assumption is that top management know the right strategy and the right norm. As such, strategic objectives and targets are formulated at the top level and subsequently deployed to objectives and targets at lower levels. Norms and objectives are financial and non-financial (Anthony and Govindarajan, 2007; Kaplan and Norton, 1996).

\subsubsection{Actor's Approach}

In contrast, the actor's approach to performance measurement originates from the assumption that the capacity of individuals who engage in actions depends on their 
individual and group circumstances, as well those of the organisation and environment. This understanding includes a pragmatic process of actors' engagement with available facts, possibilities, their individual values, and the communication intermediaries used for action. When considered from this perspective, the organisation is seen as a social construction created by human beings and their various actions. The individual is an actor who constructs their self and actions by interacting with the environment. Therefore, unlike the systems view, this approach takes into account not only individuals' potential as actors, but also local and/or specific conditions that affect their actions. The aspect of practical validity is also central to actors' engagement and actions since the response to performance measurement must originate from, and produce, a practically valid action. The design of the performance measurement system is initiated from the top, with interaction between the various groups of employees involved through dialogues. This is a reflective and dynamic process of conversation between two or more parties, during which both sides question the issue and are both creative as well as logical, for practicality purposes. This approach assumes that individuals have not only extrinsic but also intrinsic values, and that their reactions are in line with both. This distinction between the two methodologies is a continuous inquiry which can be found throughout the paper and forms part of the research questions listed at the end of the next section.

\subsection{Networks and NPM}

Other characteristics of NPM include networking, partnering, and creative collaborative arrangements within and between layers of government and the private sector. A recent study of English local governments' performance management practices showed that the network structure, and more importantly the behaviour of managers in these networks, are highly influential in shaping the management and 
performance of the organisations. The study also indicated that future research should examine networking practices in terms of connections between individuals, and that it should unpack the different types of functions (such as technical assistance or knowledge) that such networking can fulfil (Walker et al., 2010; Moynihan and Hawes, 2012). Recent research concerning public sector networks devoted only limited attention to the analysis of informal network arrangements (Baretta and Busco, 2011). This is an area that the present paper must address.

Internal and external professional networks are an important tie which connect the individual to the organisation and to the organisational field. Internal organisational networks connect the individual to the organisation, whereas inter-organisational networks build the connection between individuals in an organisational field. These networks can be formal, informal, mandated or voluntary.

Professional networks, as a form of voluntary cooperation, are part of public services. They have along been studied in public sector management and accounting literature (Pettigrew et al., 1992; Jones, 1999). In particular, health services are characterised by multiple networks of clinical, managerial and financial professionals. Studies which have conducted in-depth investigations into this topic have supported the idea that the sharing of information and the cooperation ideals of modernising governments are more suited to network forms of governance rather than hierarchies (Guven-Uslu, 2005).

\subsection{Research Questions}

Bringing together the above points, it is possible to argue that NPM has introduced a much greater emphasis on performance measures in public services. These 
developments have led to changes in the roles and responsibilities of managers, who must now take on more duties. These individuals were encouraged to actively network and share information with others in different organisations, both within and outside the public sector. Indeed, evidence in the academic literature showed that investigating managers' attitudes towards these measures is a fruitful domain, as there is evidence that implementing these new performance measures makes a difference, both in terms of responses and organisational performance. To conclude this section, below are the broad research questions that the paper is addressing:

- How do the key actors respond to a set of new performance measures in a public-sector setting? In their response, is there evidence of the systems approach and/or the actor's approach to performance measurement?

- How and to what extent do the professional networks influence key actors' individual responses and therefore the organisational managerial response to performance measures?

The next section explains the research paradigm and theoretical concepts used in this study.

\section{Paradigm of Pragmatic Constructivism}

The paper focused on the construction of managerial reality when actors are faced with the challenge of implementing a set of performance measures that they have not used before. The main aim of the present research was to develop a better understanding of performance measurement methodology and how the key actors respond to this. In particular, there was a focus on the role of professional networks in influencing this process.

There were a few reasons behind the decision to choose the paradigm of pragmatic constructivism (PC) for this study. Firstly, PC takes insights from positivism, 
rationalism, constructivism and functionalism, thus emphasising a concept of 'reality' coming from the integration of the four dimensions; indeed, PC represents the following four philosophical traditions: facts, possibilities, values and communication. The integration of these dimensions through actor(s)' interaction with the real world forms the organised reality. This integration is not a factual thing and cannot be based on a prescription; hence, human understanding, creativity and communication come into play. These are context specific, dynamic and evolving. This multiplicity of PC's philosophical features makes it a strong and adaptable paradigm in the sense that it welcomes relevant features of different theoretical positioning, used for the valid explanation of the integration. In this paper, we used certain features of the theory of social networks in order to make sense of the integration process. This is explained further in Section 3.2 below, and later in the discussion and conclusion sections.

Secondly, as a consequence of the first factor mentioned, PC is in tune with both qualitative, quantitative and mixed methodologies (Malina, Norreklit and Selto, 2011) of research which are used to investigate the integration process. However, it is essential, according to PC, to understand how the human factor influences the integration process and hence why the application of one or more qualitative methodologies would be essential. In this study, we used mostly qualitative data from interviews, observation diaries, and organisational documents. In addition to this, we used some key facts and figures from policy documents to explain the research problem and to justify the research questions. We also made use of accounting and management related facts and figures in order to investigate and explain the integration process. This is explained further in Section 4.2.

Thirdly, PC is fundamentally rooted in the practice of accounting in organisational settings. In other words, it is concerned with explaining how accounting information 
and practice are involved in the integration process. Indeed, the objective of investigation in $\mathrm{PC}$ is to examine the practice and what works for the particular setting. This was an important feature of the present study, as the data collected related to a process of active searching and learning for the actors until they were satisfied with what they had to do to implement and achieve the new targets. In addition to this, the study focused on pragmatic aims of these actions, thus making it possible to analyse the dynamic relationship between new practices and norms of accounting. This helped to explain the dynamic and shifting values, environments, and the possibilities of organisations achieving their organisational objectives. Individual actors are never the sole authors of organisational stories. The participation of multiple actors is seen as essential for this process to take place, and hence PC is predicated on multi-authored accounts rather than single-authored accounts (Norreklit, 2011) According to Mattimoe and Seal (2016), participants from both inside and outside the organisation are part of this multi-authoring process. Sections 5.3 and 5.4, which can be found below in the findings section, make use of the practice aspect and coauthoring feature of PC and explain the changes that took place during the observation of the integration process.

\subsection{Integration of Four Dimensions}

For actors to function, it is essential that the four dimensions are integrated. It is this integration which gives the organisation the power and strength to function in certain ways. As explained by Norreklit (2011, p. 21), there must first be a factual basis, which the actor is aware of and can rely upon. Factual information is essential, as it offers a reliable foundation for practical work. Following this, possibilities must be available, as without possibilities actors cannot do anything. Making alternative possibilities available is the responsibility of management. This requires active engagement with facts in a logical, reflexive and creative way to produce possibilities for the future. 
Thirdly, the values that actors believe in must be well established, so that there is sufficient motivation for the actors to act. Values are the driving forces behind actors. The fourth dimension of communication is necessary for actors to cooperate and create business. Without this, coordinated action cannot take place. Communication is key to the integration between the other dimensions as it "formats the organization as a common space of meaning" (Norreklit, 2011, p. 31). Emphasis has often been placed on the fact that communication involves coordination, interaction and social position.

One final and important condition of integration is the need for practical validity. Practical validity is the backbone of the accounting practice paradigm. For actors to act and function, the integration must include practically valid actions, as actors can only act if there is sufficient practical validity. If that is not present, then the consequence is insufficient integration. According to Norreklit (2011), this would result in illusions instead of reality. It is therefore possible to argue that practical validity is both a precondition and an outcome of integrating the four dimensions of PC.

\subsection{Management Control Topos}

When integrating the dimensions of PC, Nørreklit et al. argued that "there is no set of general principles that integrate their four dimensions of reality, rather it is a question of finding 'a company-specific' topos, where topos refer to the concepts and arguments applied in a specific setting,...” (2006, p. 43). Nørreklit et al. developed the concept of a management control topos ${ }^{i}$ as follows:

Any topos is the result of applying a conceptual framework to a specific historical situation. It consists of concepts used and common interpretations of the relevant concerns and arguments. Topoi are used for the purpose of organizing discourse, creating and modifying systems and controlling the use of such systems with a view to making decisions or plans. Although any such system has a life and effect of its own, it does not exist independently of human communication (2006, p. 48). 
The PC framework may be applied to individuals, and/or collectives such as governments and organisations. Crucially, PC does not treat either individuals or collectives as given organisms, but instead as social constructions subject to a common criterion of practical validity.

Norreklit et al. further discussed the characteristics of topoi as follows:

Topoi, then, are the concepts and arguments used in a certain social setting. They are the basic communicative tools applied to the construction of a social world. Topoi facilitate dialogues and all manner of communication between people who share the same topoi. This is why they are such powerful tools in the organizational process. The fact that they integrate a variety of subjective perspectives also explains why the topoi basically vary for each unit: they are a creative solution to the problem of coordinating the complexity of subjective perspectives. If an organization does not create its topoi with care, it cannot utilize the capacity of its members; similarly, when people from different organizations meet and try to cooperate, they face the problem of overcoming the lack of common topoi.

With reference to the above understanding of topos, this paper questioned the extent to which informal professional networks have their own topoi and how the integration of the four dimensions of reality takes place when actors in these groups are faced with a challenge or concept that they have not used before.

According to Norreklit et al. (2006, p. 60), when analysing the reality construction from one state (without waiting time targets as in the case study in this paper) to another state (where there is a waiting time target), the management topoi surrounding this process must be investigated thoroughly. These topoi are based on the reflections of managers, and can be described as a set of more-or-less implicit rules according to which one set of value-loaded facts leads to another set of value-loaded facts through a specific course of action. Topoi can therefore be described as departing from an integrated reality of which they form a part, to a future integrated reality of which they also form a part. They are a set of transformation rules, which live in a communicative system and 
integrate facts, logic and values. Indeed, many have claimed that any reasoned or wellargued management behaviour is based on valid topoi. The present paper has responded to this conclusion and has presented a detailed case study of the process.

The next section introduces the concept of 'structural holes' and discusses its connection with PC and the case study.

\subsection{Role of Structural Holes}

The concept of 'structural holes' in social network theory was developed by Burt (1992), and could provide a possible tool with which to analyse the process of integrating the four dimensions of PC into and between the layers of the professional networks explained above. While the various informal and professional networks studied here may or may not be directly connected, the concept of structural holes would, however, be useful to consider when investigating these potential connections and how these networks influence the management topoi.

Most social structures tend to be characterised by dense clusters of strong connections. Information within these clusters is, more often than not, rather homogeneous and redundant. Non-redundant or new information is most often obtained through contacts in different clusters (Burt, 1992). Contacts in a network, and in different clusters, provide information, opportunities and perspectives that can be beneficial to the central player in the network. When two separate clusters - which could possibly be networks of professionals - possess non-redundant information, there is said to be a structural hole between them (Burt, 1992). Thus, a network that bridges structural holes will provide network benefits that are, to some degree, additive, rather than overlapping. Bridges are more likely than other ties to be the source of novel, non-redundant information. Only such weak ties can be bridges (Granovetter, 1973). Social outcomes, such as receiving information about something new, are usually a function of weak ties. 
An ideal network structure has a vine and cluster structure, providing access to many different clusters and structural holes (Burt, 2004). Burt (1992) defined structural holes as a lack of connection between two nodes that is bridged by an intermediary. Networks rich in structural holes are a form of social capital, in that they offer information benefits. The main player in a network that bridges structural holes is able to access information from diverse sources and clusters. Figure 2, below, represents structural holes and the bridging role of $\mathrm{A}$ as a network node. The areas between $\mathrm{E}$ and $\mathrm{B}$, and also between $\mathrm{H}$ and $\mathrm{C}$, are defined as structural holes, where $\mathrm{A}$ is considered the bridge which makes the connection between separate networks that are not normally connected.

\section{Insert Figure 1 here}

For analysis of the data, this paper used the PC ontology in two ways. The first was by adapting the concept of structural hole to PC in order to investigate the influence of the integration of the four dimensions of reality on the generating of a new topos. In this way, the theoretical framework helps to understand the influence of external professional topoi on managerial reality construction, which in turn makes it possible to devise a new managerial topos within a particular setting. This approach attempts to entangle the connections between management control topoi in the organisation and professional topoi outside the organisation, and to establish where certain actors have individual roles to play within and between networks. It also opens up the possibility to analyse the potential influences of professional networks outside the organisation and 
how they affect, both directly and indirectly, actors' reality construction.

\section{Background of Case Study and Professional Networks}

The English National Health System (NHS) is the largest employer in Europe, comprising more than 600 organisations including service delivery organisations (such as NHS hospital Trusts and Family General Practitioners), regulators (the Care Quality Commission and Monitor), fund holding bodies (such as Primary Care Commissioning Groups), patients, and professionals.

Several modes of management exist within and between NHS organisations. The focus in this paper was on profession-based informal networks. These are outside hierarchical practices that dominate the exchange of formal information. Previous studies found that formal organisational structures and the associated formal forms of control revealed tensions in the interactive practice of medicine, thus implying increasing potential for informal networking structures (Jones, 1999).

In NHS hospitals, clinical as well as non-clinical networks play an important role when it comes to organisational structure and management. Clinical networks are influential not only within, but also between, hospitals. However, they usually remain outside direct managerial control. One of the main and most important intermediaries of clinical networks is the professional college guidelines, which make these networks diffused in nature rather than concentrated on a focal managerial network.

\subsection{Waiting Time Targets}

Waiting time targets (WTT hereafter) were introduced to the English NHS in 2000 as part of the NHS Plan (DoH, 2002); they were hailed as a new form of quality-based 
performance metric. They were a powerful tool of performance measurement and regime management post-2002, following the introduction of the Payment by Result fund allocation system. This new system introduced a revised fund allocation process to healthcare providers based on actual levels of activity and centrally determined tariff prices. The introduction of WTT was considered by the government as the ushering in of a new measure which could be used to improve quality of service and bring more of a balanced performance measurement and management system, including both quantitative and qualitative performance measures.

The focus of this paper was on WTT for Accident and Emergency (A\&E) departments. The NHS Plan, published in 2002, introduced waiting time targets for the first time to A\&E departments in the UK as follows: 'by 2004 no one should be waiting more than 4 hours in the emergency department from arrival to admission, transfer or discharge'. In 2004, this target was modified from $100 \%$ to $98 \%$ to allow for 'clinical exceptions'. For example, patients undergoing active resuscitation or those who deteriorate unexpectedly were excluded. Around the same time, financial incentives were given to those departments that were able to meet the A\&E target. Hospitals were being paid approximately $£ 100,000$ to spend on capital projects for each of the stage targets met. A survey by the British Medical Association revealed that the additional funds were usually spent centrally to make up for deficits originating in other departments of hospitals, and were not left to be spent by A\&E departments (British Medical Association, 2005).

Since its introduction in 2004, the 4-hour WTT has continued to represent a key piece of performance information for all A\&E departments in England. All departments report their performance on a weekly basis to the Department of Health. The target was 
further changed to $95 \%$ in 2010 as a result of the coalition government's claims that $98 \%$ was not clinically justified. This target is still in place today, despite criticism from various medical bodies, including the British Medical Association and the Royal College of Nursing. Indeed, on various occasions, these professional bodies declared through the media that the targets are no longer sustainable (BBC news, 17 January 2007; A\&E success 'not sustainable'; The Guardian, 14 March 2013, 'more NHS Trusts are missing the 4hours wtt, 2 April 2013 'NHS failed to meet four hour WTT', King's Fund, 2016).

Approximately 35\% of all admissions to the English NHS are classified as emergency admissions. Admitting a patient to a hospital as an emergency case is costly and frequently preventable, yet the number of emergency admissions to hospitals has been rising since the introduction of 4-hour WTT. Between 1997-98 and 2012-13, emergency admissions in England increased from 3.6 million to 5.3 million - a rise of $47 \%$ in comparison with the $10 \%$ increase in population during the same period. 5.3 million emergency admissions accounted for $67 \%$ of hospital bed days in England, costing approximately $£ 12.5$ billion (National Audit Office, 2013).

\subsection{Participants and Data Collection}

In order to assist the data analysis, a detailed case study was employed. The study followed events for approximately 12 months at a large NHS hospital. The organisation was classified as a large acute trust hospital and was located in an eastern rural region of England. During the period of study, the A\&E department treated over 100,000 patients on average per year. The hospital was in financial balance during the study period, with a total turnover of over $£ 400$ million per annum. 
The main sources of data were face-to-face interviews with key actors, documentary and archival evidence, and the researchers' field observation diaries. 24 interviews were undertaken with the following people: Chief Executive, Director of Finance, Director of Operations, clinical directors, service managers, clinical managers, clinical consultants, nurses and administrators. The majority of interviews were tape recorded and transcribed.

The approach adopted was an in-depth, longitudinal, single site study in line with various other studies concerning organisational change within the healthcare context (see, for example, McNulty and Ferlie, 2002; Jones and Dewing, 1997; Jones, 1999). Within the single site, the researchers identified several micro-levels of analysis and involved various organisational actors from different hierarchical and managerial posts. This was an important feature of the research, and served to increase the validity and authenticity of the study (Lukka and Modell, 2013). Data was analysed according to the concepts of the theoretical framework. Evidence from the observations and interview data was selected for each dimension of PC. For each of these dimensions, the effects of social network connections and the effects of structural holes were questioned with reference to relevant topoi.

The next section presents the main findings of the analysis.

\section{Findings}

This section is divided into four parts. The first part describes the management control topos at the time when the new performance measures were introduced to the NHS. It also explains each dimension of PC and the challenges the management team faced when it came to implementing new performance measures. Following this, the second part of the findings section focuses on management control at the A\&E department and how clinical and managerial teams reacted to this change. The third part provides 
a detailed explanation of how external professional networks influenced the practices in $A \& E$ and hence the integration of the four dimensions of PC. The final part of this section refers to the structural holes concept from the theory of social networks. The purpose of this is to explain how the integration of the four dimensions of PC provides evidence of new management topoi which formed after the hospital successfully met the new performance target.

\subsection{Management Topos and New Performance Measures}

During the initial phases of the fieldwork, the management topos was highly influenced by external political steer on performance measurement and institutional directives circulated through internal documentation. These documents were of a highly authoritative nature, requiring all NHS hospitals to act on the targets and report, within three months, on their progress and waiting time figures. The Chief Executive commented on this as follows:

We are required to make some changes to our performance monitoring and reporting. This is a must and we have to do this within a fairly limited time. Management and clinical leads are all aware of this. We also have dedicated individuals from top to mid level management. I can say we have a good plan in place.

It was evident that there was top management support and planning for the organisation to undertake some work in order to address the new performance measures. There was no questioning of the targets, as these were accepted as given. Indeed, an agreement was reached, without discussion, that these were the relevant performance targets to work towards.

Yes we are given these targets but of course there is a lot of history, a lot of work, and a lot of thinking behind this done by the Centre [meaning the Department of Health]. These are clearly relevant and very much about patient experience. An area perhaps we can look at more in depth. This is a good opportunity for management and clinical teams to work together. 
The concept of waiting time targets provided a clear focus for top managers and middle-level managers. The Director of Finance was given the overall responsibility of managing the new performance measurement regime. At clinical departments and in A\&E departments, an experienced Service Manager and a Clinical Manager were asked to devise an implementation plan. The Clinician Manager of A\&E commented as follows:

Waiting time targets is a new territory for me. It is exciting to know that we will be working to produce positive impact on patients' lives.... we plan to shorten the time they spend in A\&E. This is welcomed by our team as we all thrive to do this in A\&E. We will need a lot of management and time related information to find out where we are at the moment so that we can have a feasible plan to meet the target in about 6-8 months from now.

It was evident that these targets were in line with clinicians' professional values and they were highly motivated to work towards these measures. Senior management was supportive of the efforts from the clinical teams, as confirmed by the Director of Operations:

It is now down to clinical teams to find out how they will meet the waiting time targets.

There was, however, some ambiguity in relation to management data and possible ways of achieving these targets. The Service Manager commented as follows:

It is very difficult to know 'how' we will reorganize the service. We have almost no information or guideline around this. Clinicians work only with evidence and we are finding ourselves in a position where we need to create some management information or evidence for them to see and act at service level.

As noted above, in terms of the available facts and possibilities to manage and meet the waiting time targets, there was some ambiguity. Clinicians, driven by a desire for immediate action, were accustomed to basing their decisions on facts and evidence. This was not evident during the initial stages of implementation, as suggested by the Clinician Manager of A\&E: 
First we need to create a system to record this data then we need to monitor to see where we are. After that we can think about making changes at service level so that we make improvements in waiting time and meet the target.

In relation to the PC framework, there were problems with the dimensions of facts and possibilities, as the facts were not fully known and, as a result, the possibilities remained unexplored. In addition to this, there was a clear search for a practical solution. Key actors were under this pressure and were searching for more facts and possibilities. However, during the initial stages of implementation, this search did not seem to be ongoing, and hence there was no strong evidence that the four dimensions of PC were being integrated. There were several concerns surrounding 'practical validity', which was a central concern for service and clinical managers. They were asked to come up with a solution that was practically valid but that was not possible. The Service Manager commented as follows:

Central guidelines are very clear about for example the 4 hour limit in A\&E but there is not much information or guideline about how these will be done practically in $A \& E$. We are left to our own devices to find this out.

As indicated in the above quote, there were also some issues in relation to the communication of the targets, as there was a lack of clarity surrounding the guidelines, and particularly how to manage these new targets. The institutional methodology of implementation appeared to be highly mechanical, with an emphasis on the systems approach to performance measurement. The way in which the targets were introduced to the institution could be described as bearing more of a similarity to the systems approach to performance measurement. With this said, however, during the implementation phase, there were inadequacies in terms of information and management guidelines at the organisational and service level. Because of this, the relevant actors found themselves in a position to work towards creating new data and formulating their own method of rearranging the service in the way that they believed 
to be most appropriate. An internal multi-authoring (Norreklit, 2011) process was initiated at the service level in the A\&E department. These features, however, were more in line with an actor-based approach to performance measurement and were not always in line with the top down characteristic of the systems approach (Cinquini et $a l .$, 2013). This was an important moment in the fieldwork. Managerial and clinical actors started to collect various types of information and statistics about patient flow, capacity, and the main constraints of the service. This was a period of intense internal communication within the A\&E to produce a valid business case based on management evidence. In PC terms, this was a multi-authoring process during which multiple actors entered into dialogue and information sharing. This was evidenced by the changes in their business language, the various small changes to management and clinical practices, as well as the new work relations they were forming with other internal and external actors. These all confirmed the start of a more actor-based management approach. Section 2, below, focuses on the process of actor-based management in A\&E.

\subsection{Clinical topos at A\&E}

The clinical topos was highly influenced by the active information seeking of the Clinician Manager, who was collecting management and waiting time data that had been prepared by the Management Intelligence team. This resulted in the A\&E unit having to sever connections with that team. New facts and figures provided by them helped the Clinician Manager to produce a document reflecting the current status of demand and capacity issues in A\&E. Together, the A\&E Service Manager and Clinician Manager drafted a hypothetical projection for the coming months in terms 
of activity levels and the chances that the target would be met. Their comments are below:

It was evident from the current management data we were only able to see and discharge about 60 to $65 \%$ of patients within the limited time of 4 hours (Service Manager).

Current patient pathway is not adequate to achieve the target. We need to work on alternative pathways and perhaps radically redesign the service....(Clinician Manager).

These views and reports were shared within the A\&E team and then explained by both managers to directors at a management meeting. There was support from the directors, who encouraged the A\&E team to come up with some possible scenarios for service level changes.

While the Service Manager was an experienced manager with detailed knowledge of processes and capacity constraints, her comments highlighted a lack of information and practical solutions to deal with waiting time targets:

We identified the problems but it is not easy to find a solution to this... We are tied in terms of resources for infrastructure and also for having additional people...

In response to new facts about the current status of the service and limitations in relation to possibilities for the future of the service, clinical topos at A\&E showed some signs of crisis, as it was not possible to make a decision regarding service 
redesign. During the crisis period of approximately three months, new ideas were explored but no action was taken. In PC terms, this was a multi-authoring process through dialogue between various actors. Practicality was one of the major concerns, as all alternatives appeared to be either infeasible, too costly, or with a long-term focus, hence making it impossible to meet the target in a timely manner; as such, none of these alternatives were implemented. In terms of PC, it was possible to observe some traces of illusion in the clinical topos at A\&E, as there was a clear lack of integration between the four dimensions of PC.

During that crisis period, the Service Manager was actively engaging with other service managers in the region. She was part of a regional and national network of service managers. These managers were partaking in some informal communication, meetings and discussions about new performance measures. Below are some of the Service Manager's comments in relation to these networks and their impact:

Clinicians asked me about how these meetings were going. I told them that in one of the hospitals in the region, some clinicians were preparing a proposal for service redesign....This got their attention...Then our Clinician Manager came with me to the following meeting.

It was evident that a professional topos was forming between these service managers and certain clinician managers in the region. This topos was a source of new information from other hospitals about different ways in which the structure of the A\&E could be changed. These managers were freely talking about the new time measures and were sharing their experiences as well as forming their own 
professional topoi away from organisational boundaries. Indeed, the clinical topos at the A\&E was being influenced by these actions. Professional topoi occupied a shared space in between hospitals and provided a continuous stream of information and practices to all. The motivation in the professional topoi was high, as there was a shared understanding and shared professional values. These features meant that the professional topoi were inter-organisational and highly active in terms of producing and communicating possibilities for alternative service redesign and new patient pathways. The Clinician Manager explained this as follows:

We are working with another hospital and talking to clinicians there to find out a new admission and assessment route to make sure the patient is seen, diagnosed and directed within the time limits.

The clinical topos at A\&E was evolving rapidly and enthusiasm was increasing, particularly given the new evidence and examples of different pathways that were being shared and the benchmarking possibilities that were emerging. Clinician managers suggested visiting the other NHS Trust which they collected information about through the professional networks. Lead clinicians were supportive of this idea to learn how service redesign was undertaken at another hospital. They perceived this opportunity as an open forum to discuss possibilities for adapting similar procedures in their department. Below are extracts from the observations of a consultant clinician during their visit to the other NHS Trust:

...our visit proved to be very useful. They were using a piece of software in the other trust...it was not very expensive, not a big investment ... We asked senior management if we could also purchase the same software here ...

.... apart from that they had rearranged the $A \& E$ where they had an assessment 
unit in addition to normal $A \& E$ rooms. They admitted patients in the assessment unit first and then made sure that they discharged the patient within the time limit... For patients that needed longer treatment they were discharged to a treatment unit which was between the A\&E and other wards...so that they could be admitted to a ward afterwards if needed...

Clinicians at the A\&E department were convinced that after observing how the changes were working at the other trust, if applied in their department, these changes could have helped them achieve the WTT and make it sustainable. They then entered into regular communication with the other trust to understand the details of their patient pathway. This evidence provided detailed information consisting of informal, mostly nonwritten, benchmarking; this benchmarking was largely based on observation, sharing of information and discussion between the two A\&E departments. Members of the A\&E team collectively believed that a similar application could also work in their department. The changes suggested were not very costly. Moreover, these changes would provide the flexibility and new pathway opportunities needed to improve and speed up the service.

Informal professional networking outside the organisation was an important social tie for clinician managers in terms of getting connected and forming a network bridge between the departments of two different hospitals.

\subsection{Internalising Professional Topos and Integrating the Four Dimensions}

Observations and facts collected during the visit to another A\& E department were the key pieces of information that the clinician managers and service managers shared with the board members. There was some level of conflict between the top managers and clinician managers. This was evidence of a process by which the professional topos was influencing the management topos through structural holes where clinician managers 
were in action. In terms of PC, this was a key process, and constituted further evidence of coauthoring between the clinical topos and the management topos. This is explained below with reference to specific events and actions.

Clinician managers were asking for some changes in reconfiguring a new patient pathway and for investment in the wards to redesign the rooms in A\&E; they also wanted to buy a new software package to keep track of real-time data in the department. They explained to board members that they had seen what the other A\&E department was doing and that it was working well. As a result, they expressed a willingness to implement similar changes in their department. This request was followed by a 3 or 4 week period of bargaining and persuasion between the clinicians and the board members:

We asked for simple partitioning of the space and rearranging of some beds. The software was not expensive, ...There were discussions and some questions...We mentioned other A\&Es are also doing similar changes...I heard one of London area service is also doing something along the same lines... Over a period of a couple of months, we had the new structure up and running (Clinician manager, $A \& E$ ).

This software is useful, helps me to follow which patients are in the A\&E at the moment... When these patients entered through the door and what time they need to be out... I know exactly what this particular patient is waiting for (Service manager, $A \& E$ ) (while showing the researchers how the software worked).

After a number of meetings, the proposed changes went through a process of adaptation and were accepted after approximately two months of planning and discussions. With the introduction of the new software and computerised system, everybody in the team became aware of real-time waiting time data on their screen at all times. In addition to this, there were some physical changes in the department. Two smaller sub departments in A\&E were built. The first one was an assessment and discharge sub unit for patients who would be seen and discharged within the 4-hour waiting time. The second sub unit was for more serious cases that required longer 
treatment or for cases that needed to be taken as new admissions to the hospital. These changes guided the design of new patient pathways, and hence a new administrative system of record keeping and management was set up. Although it was not essential to increase the number of clinical staff, it was evident that more administrative staff and increased paperwork would be one of the outcomes of these changes. One of the A\&E Nurses commented as follows in relation to changes that they experienced in the department:

...WTTs completely changed the way we do our services and how we deal with patients waiting in $A \& E . .$. (A\&E Nurse). It is a big change and stressful most of the time...

Other clinicians agreed with these views and emphasised that there were very apparent changes in the department and in the way the service was delivered. New work processes were in place. Staff were continuously learning and adapting to new processes and recording systems. There was a supportive and positive spirit in the work environment, but there was also a certain level of stress, as the changes were drastic and the outcome of these changes was unknown at the time. On the other hand, the professional drive behind the changes for service improvement kept the team together and helped them during difficult times. These changes were slowly being infused into the everyday language of the A\&E department and there were subtle changes in everyday practices. There was emerging evidence that the management topos was being affected as the new waiting time performance measures entered into daily practices. This resulted in a new attitude and new structures of control being infused into routine activities.

The section below explains these changes, with reference to the theoretical framework; it also discusses the role of structural holes in integrating the four dimensions of PC and their influence on the modified managerial topos. 


\subsection{Structural Holes and a New Management Topos}

Clinician managers in the study appeared to have the characteristics of a bridge in structural holes located between established sets of different professional networks. As shown by Figure 1, it might be possible to suggest that node E, as a Clinician Manager, connects to a Service Manager (node A), as part of their clinical network. However, A makes the connection to node B as well as to node $\mathrm{C}$, both of which could be located outside or inside the organisation. This is similar to a Clinician Manager making connections with Management Intelligence (e.g. E connects to B) and again with another Clinician Manager in another hospital (e.g. E connects to C). These connections bring new knowledge to $\mathrm{E}$ and to their network. These weak connections form the structural holes. In the case study, a structural hole existed between the clinical topos in $\mathrm{A} \& \mathrm{E}$ and the professional topos outside the organisation. The service managers were making the connection, but it was actually the clinician managers through whom, to a large extent, the learning and sharing of information took place. The Service Manager is connected to a professional network. Without the connection between the Clinician Manager and Service Manager, the professional network would not be able to connect to the Clinician Manager, and this person would not have visited the other A\&E department. If that were the case, then it would not be possible to bring benchmarking data and new clinical practices into the organisation. In addition to this, without the support of other clinicians in the network (such as F, D, and H in Figure 1) the transfer of information and knowledge between these separate networks might not have been possible. It is through these layers of communication that new possibilities were explored and were observed. It is important to note that the professional values of all these individuals were in harmony and they had a common and a very clear goal of 
meeting the waiting time target.

The clinician managers and service managers in this study were able to act like bridges between these two communities and topoi. They were information intermediaries through whom experiences were shared and new possibilities were suggested and explored. Figure 2, below, attempts to demonstrate these connections.

This transfer of knowledge and experience was influential in forming the new management topos.

With reference to PC, strong professional values always supported this process of change in topos, from lack of integration to a healthier integration forming a more harmonious management topos towards the end of the fieldwork. New facts, observations and possibilities were injected into the management topos through the structural holes. Communication between clinician managers and service managers, both within and outside the organisation, was informal, and focused on professional norms and a search for 'what works'. This was a search for practical validity, which is an essential ingredient and outcome of integration for PC. Practical validity was assured and shared in professional networks, thus making the integration of the four dimensions smoother and more coherent than at the beginning of the fieldwork. Communication was based on professional trust and a common strong work ethic. Integration was therefore more harmonious, leaving the period of crisis in the past and leading the organisation into a phase of dynamism and action. These were notable changes in the clinical topos of the A\&E. Indeed, the changes reflected on the management topos of the organisation, as the new performance measures were one of the top priorities of the organisation. This was further evidence of the coauthoring process between the A\&E department and the top management team. The A\&E department reached their waiting 
time target for the first approximately 12 months after starting the implementation process. The comments below illustrate the change in the management topos and how positively the change was perceived:

We have been through a difficult time but we trusted our clinical teams. They did a fantastic job in collaboration with others from the Region. We supported the process as much as possible with resources and anything else that we could do. We are now at a position to say that we have this under control and we know what we are doing...This is having such a positive impact for all the other departments (Director of Finance).

We are having a staff ceremony to congratulate our A\&E team for their achievement. This is a success story to share in the organization. I am sure other teams will follow the method A\&E applied for meeting the targets (Chief Executive).

\section{Insert Figure 2 here}

\section{Discussion: Systems vs Actor's Approach}

As stated above, throughout this paper, there has been an underlying theme of searching for evidence of performance measurement methodology. The aim of this was to find evidence regarding the use of the systems approach and actor's approach for performance measurement. The first part of the discussion below addresses this underlying theme and provides some answers to the first research question of the paper. Following this, the second part of the discussion refers to the unique attributes of PC ontology for the case study. The final part of discussion revisits the concept of structural holes and explores its influence on the case study in terms of the successful integration 
of the four dimensions of PC

The case study analysis and interview data clearly showed that there were traces of both of these distinct methodologies. At the start of the fieldwork, and for the first few months, there were various forms of documentation and observational evidence indicating more of a systems approach to performance measurement. Both policy documents and internal reports in the organisation were of an authoritative nature, with clear facts, figures and deadlines. Responsibilities were strictly defined and named individuals were in charge of taking care of these responsibilities. A very much top down and centrally determined approach to performance measurement was in place. Support from management teams and responsible individuals was not questioned or discussed and was accepted as given. This initial period of central control was followed by a short period of crisis during which not much action was taken in terms of implementation or progress in the organisation. During that period, certain key actors who were assigned new roles and responsibilities to undertake some changes at department and service level, were actively seeking individual and group-based solutions to problems of implementation. These attempts were actor-centred and showed characteristics of a bottom up change. These attempts and responses were not planned or expected. From that moment onwards, there a huge amount of evidence emerged showing the benefits of the actor-based approach to performance measurement in the organisation. Dialogue, discussion, reflection and creativity were in place both within and outside the organisation as key actors entered into discussions and information sharing with other hospitals through individuals with similar responsibilities. These actors were influential in making the implementation plans a reality. 
The above discussion implies that it is sometimes necessary to consider multiple or mixed methodological approaches (Malina et al., 2011) to performance measurement. In particular, public sector settings might require this more than others. Employees of public sector organisations are accustomed to working under the strictly governed rules and regulations of governments and various institutions. For these individuals it might not appear natural to take on key actor positions and assume this impactful responsibility in situations where they have limited knowledge or experience. Indeed, it is probably for this reason that the case study organisation went through a period of crisis, with limited action in relation to new performance measures. It would be desirable if, in devising performance measurement plans for the public sector, an assumption could be made that some actors in organisational settings will need to be in charge of new responsibilities and take on active roles related to issues that are completely new to them. For these situations, both organisational and interorganistional spaces could be defined or devised when relevant information is found and shared. It is, however, essential to note that these spaces would need to bring together an appropriate set of professional values, a relevant set of facts, alternative possibilities, and clear communication channels if purposeful solutions are to be fostered. These characteristics are the four dimensions of PC; indeed, it would be useful to consider and purposefully include these in any performance measurement plan, which takes into account the role of key individuals as actors of management plans.

With reference to PC ontology and the integration of the four dimensions of reality, the case gave rise to a good example where there was a less-than-ideal scenario at the start of the implementation process. This was due to the lack of a practically valid solution. Then, with the key actors taking active responsibility for finding a practical solution, 
results started to emerge. These managers were able to bring in new facts, new information, and new experiences; this led to new alternatives and possibilities which stemmed from their professional connections outside the organisation. As these new facts and possibilities were very much in line with professional and organisational values, they were warmly welcomed by the members of the implementation teams and top managers in the organisation. In addition to this, communication intermediaries were not rigidly defined and were based on informal connections, meaning they were extremely flexible and open to creativity. All of these characteristics turned the adaptation and implementation process into a concerted effort. This meant that the four dimensions of PC had a strong influence on the implementation process so that integration between them was achieved. The coauthoring of key actors and their search for practical solutions were welcomed by the organisation and hence a new clinical and management topos was in place in the organisation as a result of this process.

In relation to structural holes, the case study provided a good example to show that certain key actors were highly influential during the integration process of the four dimensions. At this point it is possible to refer to the social capital concept put forth by Burt (2000) and Granovetter (1983). They argued that the structural holes in a social network offer the potential of social capital. Indeed, some studies have suggested that this type of social capital created opportunistic behaviour (Inkpen and Tsang, 2005). This possibility opens up the discussion of whether or not this could be the cause of any future or possible problems for the case study organisation. PC provides a possible answer or further discussion point in this regard through its dimension of values. It is essential that any integration process remain in touch with the values dimension, reflective accounts, and dialogue between organisational actors. This is an ongoing and evolving consideration. as actors would be expected to follow or remain loyal to their 
professional and ethical considerations during all of their practices.

Another important issue in the case was the fact that key actors had a significant role to play, and there were only very few ( 2 or 3 in this case) managers who initiated and championed the implementation plan. This feature made it difficult for the organisation to see or to judge whether or not this particular practice was risky, and whether it was the right thing to do. If suggested changes are not well debated by wider participation in the organisation where subjective values of the actors are expressed (Trenca, 2016), then in PC terms, it is not certain that the integration will produce lasting results. Wider participation would mean participation not only from key actors, but also other managers from various levels of the organisation as well as certain representatives of service level employees, accountants, and other support staff. Indeed, if discussions are undertaken by all of these parties, then it would be possible to maintain an overall organisational view of the proposed practice. Furthermore, PC also foresees that such a lack of wider support and concerted belief could lead to undesired results, such as illusions instead of the creation of successful realities for the organisation (Norreklit, 2011).

\section{Concluding Comments}

This paper reported findings from a case study where key actors interacted with a set of new non-financial time-based targets in a large hospital belonging to the English National Health Service. The purpose was to find out how the key actors responded to these new performance measures and to establish whether there was any evidence of the systems approach and/or actor's approach to performance measurement. Moreover, the study also aimed to ascertain how, and to what extent, professional networks influenced the responses of key actors, as well as the organisation's managerial 
response to the performance measures.

The methodological approach to managing these new measures was investigated and evidence was collected to identify the systems approach and actor's approach to performance measurement at different stages of the implementation process. This was discussed above. The study focused on conducting a detailed analysis of actors' attitudes towards these measures and investigated their actions and responses, with particular reference to their professional interactions and learning experiences. As the performance measures were new to managers, there was a lack of knowledge and experience regarding how to implement them. They actively engaged in uncovering information and data, both inside and outside the organisation. It was natural to some of them to ask other colleagues and/or any external networks they were part of. Informal professional networks outside the organisation provided an ideal platform for these managers to share their concerns about the new measures, to ask questions, and to share experiences. Through this interaction, certain solutions to the implementation problems became apparent. A benchmarking exercise between the studied organisation and another hospital in the region provided some solutions. These were adapted and put in place in order to improve the likelihood of performance targets being achieved.

Although this was a single site study and it was not possible to generalise the findings, the study provided some important indicators in terms of the direction of future studies. It was evident that in situations where a new set of performance measures is being implemented but there is limited knowledge and expertise, key actors will be inclined to search for new information and the experiences of others. It is likely that these individuals will reach outside the organisation and attempt to bring new knowledge and practices into their organisation. It is therefore essential to study how these interactions 
take place and how new practices are brought in. For public sector research, this might necessitate the more in-depth investigation of systems and actor-based practices. Indeed, this could show that it is possibly advisable to bring these two approaches together in policy making and organisational implementation plans. 


\section{REFERENCES}

Anthony, R.N. and Govindarajan, V. (2007), Management Control Systems, McGrawHill, Singapore.

Baretta, A. and Busco, C. (2011), "Technologies of government in public sector's networks: in search of cooperation through management control innovations", Management Accounting Research, Vol. 22, pp. 211-219.

British Medical Association (2005), BMA Survey of A\&E Waiting Times, British Medical Association, London.

Burt, R. (1992), Structural Holes: The Social Structure of Competition, Harvard University Press, Cambridge, MA.

Burt, R. (2000), "Structural holes versus network closure", in Lin, N., Cook, K.S. and Burt, R.S. (Eds.), Social Capital: Theory and Research, de Gruyter, Aldine.

Burt, R. (2004), "Structural holes and good ideas", American Journal of Sociology, Vol. 110, pp. 349-39..

Cinquini, L., Mitchell, F., Norreklit, H. and Tenucci, A. (2013), "Methodologies for managing performance measurement", in Mitchell, F., Norreklit, H. and Jakobsen, M. (Eds.), The Routledge Companion to Cost Management, Routledge, Abingdon, Oxon, pp. 360-379.

Department of Health (2000), The NHS Plan: A Plan for Investment, A Plan for Reform, Department of Health, London.

Ferlie, E., Pettigrew, A., Ashburner, L. and Fitzgerald, L. (1996), The New Public Management in Action, Oxford University Press, Oxford.

Granovetter, M. (1973), “The strength of weak ties”, American Journal of Sociology, Vol. 78 No. 6, pp. 1360-1380.

Granovetter, M. (1983), "The strength of weak ties: a network theory revisited", in Collins, R. (Ed.), Sociology Theory, Jossey Bass, San Francisco, CA, pp. 201233.

Guven-Uslu, P. (2005), "Uses of performance metrics in clinical and managerial networks", Public Money and Management, Vol. 26 No. 2, pp. 95-100.

Hood, C. (1991), “A public management for all seasons?”, Public Administration, Vol. 69 No. 1, pp. 3-19.

Hood, C. (1996), "Exploring variations in public management reform of the 1980's", in Bekke, H.A., Perry, J.L. and Toonen, T.A. (Eds.), Civil Service Systems in Comparative Perspective, Indiana University Press, Bloomington, IN. 
Hood, C. (1998), The Art of The State: Culture, Rhetoric and Public Management, Oxford University Press, Oxford.

House of Commons (2005), "Department of Health: improving emergency care in England", Sixteenth report of session 2004-2005.

Hughes, O.E. (2003), Public Management and Administration, $3^{\text {rd }}$ ed., Palgrave MacMillan, Basingstoke.

Inkpen, A. and Tsang, E.W.K. (2005), "The social capital, networks and knowledge transfer", Academy of Management, Vol. 30 No. 1, pp. 146-165.

Jones, C.S. (1999), "Hierarchies, networks and management accounting in NHS hospitals", Accounting Auditing and Accountability, Vol. 12 No. 2, pp. 164187.

Jones, C.S. and Dewing, I.P. (1997), "The attitudes of NHS clinicians and medical managers towards changes in accounting controls", Financial Accountability and Management, Vol. 13, No.3. pp. 261-280.

Kaplan, R.S. and Norton, D.P. (1992), "The balanced scorecard: measures that drive performance", Harvard Business Review, January-February, pp. 71-79.

King's Fund (2016), "What's going on in A\&E? The key questions answered", available at: https://www.kingsfund.org.uk/projects/urgent-emergencycare/urgent-and-emergency-care-mythbusters (accessed 01.02.2017)

Lukka, K. and Modell, S. (2010), "Validation in interpretive management accounting research”, Accounting Organizations and Society, Vol. 35, Issue 8, pp. 462-477.

Malina, M., Nørreklit, H. and Selto, F.H. (2011), "Lessons learned: advantages and disadvantages of mixed method research", Qualitative Research in Accounting \& Management, Vol. 8 No. 1, pp. 59-71.

Mattimoe, R. and Seal, W. (2016), "The role of narrative in developing management control knowledge from fieldwork", Qualitative Research in Accounting \& Management, Vol. 13 No. 3, pp. 330-349.

McLaughlin, E., Muncie, J. and Hughes, G. (2001), "The permanent revolution: new labour, new public management and the modernization of criminal justice", Criminology and Criminal Justice, Vol. 1 No. 3, pp. 301-318.

McNulty, T and Ferlie, E (2002), Reeingineering Health Care: The Complexities of Organizational Transformation, Oxford University Press, Oxford.

Moynihan, D. and Hawes, D. (2012), "Responsiveness to reform values: the influence of the environment on performance information use", Public Administration Review, Vol. 72 No. 1, pp. 95-105. 
National Audit Office (2013), "Emergency admissions to hospital: managing the demand", available at: http://www.nao.org.uk/wpcontent/uploads/2013/10/10288-001-Emergency-admissions.pdf (accessed $\underline{01.02 .2017}$

NHS Services (2013), "Seven days a week forum", available at: http://www.england.nhs.uk/wp-content/uploads/2013/12/evidence-base.pdf (accessed 01.02.2017)

Nørreklit, L., Nørreklit, H. and Israelsen, P. (2006), "The validity of management control topoi: towards constructivist pragmatism", Management Accounting Research, Vol. 17, pp. 42-71.

Nørreklit, H., Nørreklit, L. and Mitchell F. (2010), "Towards a paradigmatic foundation for accounting practice", Accounting Auditing and Accountability, Vol. 23 No. 6, pp. 733-758.

Nørreklit, L. (2011), “Actors and reality: a conceptual framework for creative governance", in Jakobsen, M., Johansson, I. and Nørreklit, H. (Eds.), An Actor's Approach to Management, Djof Publishing, Copenhagen, pp. 7-38.

Nørreklit, H., Raffnsoe-Moller and Mitchell, F. (2016), “A pragmatic constructivist approach to accounting practice and research", Qualitative Research in Accounting \& Management, Vol. 13 No. 3, pp. 266-277.

Nuffield Trust (2012), Evidence for Better Health Project, Nuffield Trust, London.

Pettigrew, A.M. (1987), "Context and action in the transformation of the firm", Journal of Management Studies, Vol. 24 No. 6, pp. 649-670.

Pettigrew, A., Ferlie, E. and McKee, L. (1992), Shaping Strategic Change, Sage Publications: London.

Pollitt, C. and Bouckaert, C. (2000), Public Management Reform, Oxford University Press, Oxford.

Trenca, M. (2016), "Tracing the becoming of reflective practitioner through the enactment of epistemic practices", Qualitative Research in Accounting \& Management, Vol. 13 No. 3, pp. 350-369.

Walker, R., Andrews, R., George, A., Boyne, K., Meier, J. and O’Toole, L.J. Jr. (2010), "Wakeup call: strategic management, network alarms, and performance", Public Administration Review, Vol. 70 No. 5, pp. 731-741.

\footnotetext{
${ }^{\mathrm{i}}$ Topos is singular; topoi is plural.
} 